\title{
Response surface methodological study on lipase-catalyzed synthesis of amino acid surfactants
}

\begin{abstract}
Lipozyme (Rhizomucor miehei lipase) was used to catalyze the acylation of the amino acid llysine (L) with the free fatty acids, palmitic (PA) and oleic (OA) acids, to synthesize N-

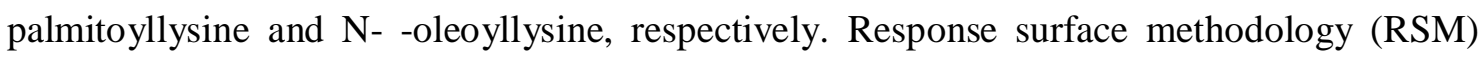
based on a five-level, five-variable design was employed, firstly, for studying the interactive effects of various parameters on the reactions, and secondly, for their optimization. Simultaneously increasing temperature and solvent hydrophobicity, fatty substrate concentration or enzyme amount improved yields in both reactions, as did increasing solvent hydrophobicity and substrate concentration or enzyme amount, and substrate concentration and enzyme amount together. Increasing desiccant amount in very non-polar solvents, at very high levels of enzyme, and in very concentrated substrate solutions led to higher yields in the $\mathrm{PA}$ reaction but compromised the $\mathrm{OA}$ reaction. The optimum conditions predicted for the two reactions were: temperature, $69.3 \check{\mathrm{C}}$ (PA) and $56.6 \check{\mathrm{C}}(\mathrm{OA})$; solvent $\log \mathrm{P}=3.46$ (PA) and $\log \mathrm{P}=3.50(\mathrm{OA})$; fatty substrate concentration, $98.0 \mathrm{mM}(\mathrm{PA})$ and $99.9 \mathrm{mM}(\mathrm{OA})$; enzyme amount, $186 \mathrm{mg}$ (PA and OA); molecular sieves, $160 \mathrm{mg}$ (PA) and $80 \mathrm{mg}$ (OA). Reactions

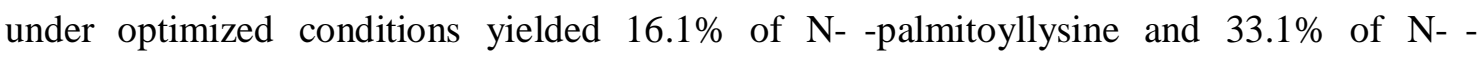
oleoyllysine.
\end{abstract}

Keyword: Amino acid surfactants; Enzymatic synthesis; Lipase; Response surface methodology (RSM); Free fatty acids; L-Lysine 